\title{
Electronic and optical properties of $\mathrm{Mn}-\mathrm{S}$ co-doped anatase $\mathrm{TiO}_{2}$ from first-principles calculations
}

\author{
GuohaO Wu ${ }^{1,2}$, S.K. Zheng ${ }^{1,2,3, *}$, XiAObING YAN ${ }^{2}$ \\ ${ }^{1}$ Research Center for Computational Materials \& Device Simulations, Hebei University, Baoding 071002, P.R. China \\ ${ }^{2}$ College of Electronic \& Information Engineering, Hebei University, Baoding 071002, P.R. China \\ ${ }^{3}$ Department of Analytical Chemistry, Campus Universitario de Rabanales, Universidad de Córdoba, Córdoba 14071, Spain
}

The electronic and optical properties of $\mathrm{Mn}-\mathrm{S}$ co-doped anatase $\mathrm{TiO}_{2}$ were calculated using the plane-wave-based ultrasoft pseudopotential density functional method within its generalized gradient approximation (GGA). The calculated results show that the band gap of $\mathrm{Mn}-\mathrm{S}$ co-doped $\mathrm{TiO}_{2}$ is larger than that of the pure $\mathrm{TiO}_{2}$, and two impurity bands appear in the forbidden band, one of which above the valence band plays a vital role for the improvement of the visible light catalytic activity. The $\mathrm{Mn}-\mathrm{S}$ co-doped anatase $\mathrm{TiO}_{2}$ could be a potential candidate for a photocatalyst because of its enhanced absorption ability of visible light.

Keywords: $\mathrm{Mn}-\mathrm{S}$ co-doped $\mathrm{TiO}_{2}$; electronic structure; optical properties

(C) Wroclaw University of Technology.

\section{Introduction}

Anatase titanium dioxide $\left(\mathrm{TiO}_{2}\right)$, which is wellknown as a cheap, nontoxic, stable semiconductor material, has attracted much attention in recent decades as an interesting material for solar cells applications and the most promising photocatalyst [1-3]. However, the pure anatase $\mathrm{TiO}_{2}$ has low energy conversion efficiency and, because of its fundamental band gap of $3.23 \mathrm{eV}$, absorbs only a small portion of the solar energy in the ultraviolet region (UV) which corresponds to 3 to $5 \%$ of the sunlight. Recently, many attempts, such as surface sensitization [4], composite semiconductor coupling [5], and ion doping [6-10], have been carried out to modify the band structure of $\mathrm{TiO}_{2}$. Among these methods, doping is regarded as a promising way to modify the band edges of $\mathrm{TiO}_{2}$ and extend its photocatalytic activity to the visible spectrum, and various kinds of dopants, such as $\mathrm{N}, \mathrm{C}, \mathrm{S}, \mathrm{Cu}, \mathrm{W}, \mathrm{Mn}$ [11-16], have been used to achieve the goal. Mono-doped $\mathrm{TiO}_{2}$ can respond to the visible light and broaden the optical absorption

*E-mail: zhshk@126.com region; however, the introduction of impurity bands can easily create recombination centers for electrons and holes, which is not beneficial for activity improvement of the photocatalysts. Recent studies have shown that anion-cation co-doping can significantly improve the photocatalytic activity of $\mathrm{TiO}_{2}$, as the co-doping ions can reduce the recombination centers and effectively improve the charge carriers migration efficiency, therefore, enhance the photocatalytic activity of $\mathrm{TiO}_{2}$ [17].

Many studies have been performed to investigate the effects of $\mathrm{Mn}$ and $\mathrm{S}$ mono-doping on the optical absorption of $\mathrm{TiO}_{2}$. Umebayashi et al. $[13,18]$ successfully synthesized S-doped $\mathrm{TiO}_{2}$ $\left(\mathrm{S} / \mathrm{TiO}_{2}\right)$ by oxidation annealing of $\mathrm{TiS}_{2}$. They found that the $\mathrm{S}$ atoms replaced $\mathrm{O}$ atoms and the $\mathrm{S} / \mathrm{TiO}_{2}$ showed optical redshift. Cui et al. [19] calculated the electronic structures and optical absorption spectra of $\mathrm{S} / \mathrm{TiO}_{2}$ by means of first-principles calculations. The results indicated that the isolated S $3 p$ states that appeared at the upper edge of the valence band caused the narrowing of the band gap of $\mathrm{S} / \mathrm{TiO}_{2}$; Zhang et al. [20] prepared Mndoped $\mathrm{TiO}_{2}\left(\mathrm{Mn} / \mathrm{TiO}_{2}\right)$ films by sol-gel method. They found that the sample with the dopant 
concentration of 0.7 at.\% had the highest activity based on the degradation rate of methyl orange. $\mathrm{Bi}$ nas et al. [21] synthesized $\mathrm{Mn} / \mathrm{TiO}_{2}$ nanostructured powders by sol-gel method, and they found that the photocatalytic activity of $0.1 \% \mathrm{Mn}: \mathrm{TiO}_{2}$ was higher than that of the other photocatalytic materials with different concentrations $(0.5 \%$ and $1 \%)$ under both UV and visible light.

As far as we know, neither experimental nor theoretical studies have been reported on the $\mathrm{Mn}-\mathrm{S}$ co-doped anatase $\mathrm{TiO}_{2}\left(\mathrm{Mn}-\mathrm{S} / \mathrm{TiO}_{2}\right)$. Therefore, in this paper, the plane-wave-based ultrasoft pseudopotential method, based on the density functional theory within the GGA, has been utilized to obtain a fundamental insight into the effects of $\mathrm{Mn}-\mathrm{S}$ co-doping of the anatase $\mathrm{TiO}_{2}$, aiming at prediction of the interplay of the co-dopants on the energy band structure of anatase $\mathrm{TiO}_{2}$ and providing a theoretical basis for the experimental study.

\section{Calculation model and method}

Anatase $\mathrm{TiO}_{2}$ has a tetragonal structure (space group: $\mathrm{I} 4_{1} / \mathrm{amd}$, local symmetry: $\mathrm{D}_{4 \mathrm{~h}}^{19}$ ), and contains four $\mathrm{Ti}$ atoms and eight $\mathrm{O}$ atoms in the primitive cell. The doping system was constructed from a relaxed $(3 \times 3 \times 1) 108$-atom anatase supercell. The large supercell was used to minimize possible artificial Coulomb interactions between impurity ions in neighboring supercells. In order to reduce the influence of boundary effects, the central $\mathrm{Ti}$ atom was replaced by $\mathrm{Mn}$ and the neighboring $\mathrm{O}$ by $\mathrm{S}$. The doping model is shown in Fig. 1, with the corresponding doping concentrations of 0.93 at.\% for mono-doping and 1.85 at.\% for co-doping.

The non-spin-polarized density functional theory (DFT) calculations were performed by the CASTEP [22] program on the basis of the plane-wave method within a generalized gradient approximation, with the exchange-correlation function of Perdew-Burke-Ernzerhof (PBE). The interactions between valence electrons and the ionic core were described by ultrasoft pseudopotential, which was used with Ti: $3 s^{2} 3 p^{6} 3 d^{2} 4 s^{2}$, O: $2 s^{2} 2 p^{4}, \quad M n: 3 d^{5} 4 s^{2}$ and $S: 3 s^{2} 3 p^{4}$ as

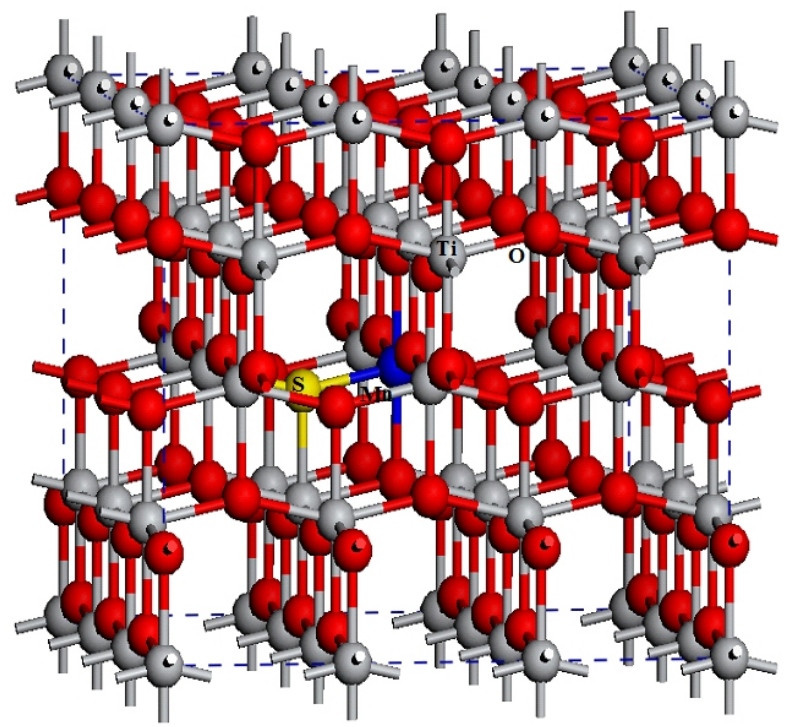

Fig. 1. Structural model of the $\mathrm{Mn}-\mathrm{S} / \mathrm{TiO}_{2}$.

the valence electrons configuration. We chose the cut-off energy of $300 \mathrm{eV}$ for all the computations. The special points sampling integration over the Brillouin zone was carried out using the Monkhorst-Pack method with a $2 \times 2 \times 2$ special-point mesh. All of the structures were allowed to relax using the BroydenFletcher-Goldfarb-Shanno (BFGS) quasi-Newton scheme with the convergence threshold for the maximum energy change of $2.0 \times 10^{-5} \mathrm{eV} /$ atom, and the maximum force, maximum stress and maximum displacement tolerances set as $0.05 \mathrm{eV} / \AA$, $0.1 \mathrm{GPa}$, and $0.002 \AA$, respectively. These parameters are sufficient for well-converged total energy and structural transition calculations.

\section{Results and discussion}

\subsection{Structural properties and formation energies}

After geometry optimization, the lattice parameters were $\mathrm{a}=\mathrm{b}=3.8078 \AA$ and $\mathrm{c}=9.8213 \AA$, which was in good consistency with experimental [23] and theoretical [24] data.

To examine the relative difficulties of incorporating different ions into the lattice, the dopant 
formation energies were calculated according to the formula below:

$$
E\left(S / \mathrm{TiO}_{2}\right)_{\text {form }}=E(\text { doped })-E(\text { pure })-\mu_{S}+\mu_{O}
$$

$$
\begin{aligned}
E\left(\mathrm{Mn} / \mathrm{TiO}_{2}\right)_{\text {form }}= & E(\text { doped })-E(\text { pure }) \\
& -\mu_{M n}+\mu_{T i} \\
E\left(\mathrm{Mn}-\mathrm{S} / \mathrm{TiO}_{2}\right)_{\text {form }}= & E(\text { doped })-E(\text { pure }) \\
& -\mu_{M n}-\mu_{S}+\mu_{O}+\mu_{T i}
\end{aligned}
$$

where $\mathrm{E}$ (doped) is the total energy of $\mathrm{TiO}_{2}$ with dopant, and $\mathrm{E}$ (pure) is the total energy of the supercell of pure $\mathrm{TiO}_{2}, \mu_{\mathrm{S}}$ is the chemical potential of $\mathrm{S}$, which is determined by the energy of $\mathrm{SO}_{2}$ molecule $\left(\mu_{\mathrm{S}}=\mu_{\mathrm{SO}_{2}}-\mu_{\mathrm{O}_{2}}\right), \mu_{\mathrm{Mn}}$ represents the calculated chemical potential of $\mathrm{Mn}$ from bulk atoms. The growth of an engineered $\mathrm{TiO}_{2}$ is not an equilibrium process but a variable determined by a growing environment [25], which can be either Ti-rich, O-rich, or anything in-between. Under Ti-rich conditions, the $\mu_{\mathrm{Ti}}$ chemical potential is assumed to be the energy of bulk $\mathrm{Ti}$, while the $\mu_{\mathrm{O}}$ chemical potential is determined by the following formula:

$$
2 \mu_{O}+\mu_{T i}=\mu_{T i O_{2}}
$$

Under O-rich conditions, the $\mu_{\mathrm{O}}$ chemical potential is calculated from the ground-state energy of the $\mathrm{O}_{2}$ molecule $\left(\mu_{\mathrm{O}}=1 / 2 \mu_{\mathrm{O}_{2}}\right)$, while $\mu_{\mathrm{Ti}}$ is obtained by formula 4 . The calculated formation energies are listed in Table 1.

Table 1. Formation energies (eV) $\mathrm{E}_{\text {form }}$ for $\mathrm{Mn}, \mathrm{S}$, and $\mathrm{Mn}-\mathrm{S}$ co-doped $\mathrm{TiO}_{2}$.

\begin{tabular}{ccc}
\hline $\mathrm{E}_{\text {form }}$ & Ti-rich & O-rich \\
\hline \hline Mn-doped & 7.00083 & -3.60248 \\
S-doped & 3.96403 & 9.26558 \\
Mn-S codoped & 9.99344 & 4.69175 \\
\hline
\end{tabular}

From Table 1 it can be seen that under Ti-rich condition, the formation energies of the three kinds of doping are positive, which indicates that if these three kinds of doping were carried out in the experiment, it would be a thermonegative reaction.
On the other hand, under O-rich condition, the results indicate that the experiments of S-doping and $\mathrm{Mn}-\mathrm{S}$ co-doping should be thermonegative reactions, but Mn-doping experiment should be an exothermic reaction. By comparison of the data on formation energies, we concluded that the $\mathrm{Mn} / \mathrm{TiO}_{2}$ and $\mathrm{Mn}-\mathrm{S} / \mathrm{TiO}_{2}$ are easy to form in oxygen enrichment condition. However, the $\mathrm{S} / \mathrm{TiO}_{2}$ is easy to form in titanium enrichment condition.

\subsection{Population analysis and electron density}

The charge density on the $\left(\begin{array}{lll}0 & 0 & 1\end{array}\right)$ surfaces of $\mathrm{TiO}_{2}, \mathrm{Mn} / \mathrm{TiO}_{2}, \mathrm{~S} / \mathrm{TiO}_{2}$ and $\mathrm{Mn}-\mathrm{S} / \mathrm{TiO}_{2}$ were plotted to study the origin of the band gap modifica-

\begin{tabular}{|c|c|c|c|c|c|}
\hline Species & $\mathrm{s}$ & $\mathrm{p}$ & d & Total & charge $[\mathrm{e}]$ \\
\hline $\mathrm{Mn} / \mathrm{TiO}_{2}: \mathrm{Mn}$ & 0.30 & 0.32 & 5.44 & 6.06 & 0.94 \\
\hline $\mathrm{S} / \mathrm{TiO}_{2}: \mathrm{S}$ & 1.80 & 4.54 & 0.00 & 6.34 & -0.34 \\
\hline $\mathrm{Mn}-\mathrm{S} / \mathrm{TiO}_{2}: \mathrm{Mn}$ & 0.29 & 0.36 & 5.59 & 6.24 & 0.76 \\
\hline $\mathrm{Mn}-\mathrm{S} / \mathrm{TiO}_{2}: \mathrm{S}$ & 1.82 & 4.35 & 0.00 & 6.17 & -0.17 \\
\hline
\end{tabular}
tions, the charge distribution and transfer caused by Mn-S co-doping, as shown in Fig. 2. The atomic populations of dopants in the doping systems are listed in Table 2.

Table 2. Atomic populations of doped $\mathrm{TiO}_{2}$ supercell.

From Table 2 we can know that the charge of $\mathrm{Mn}$ in $\mathrm{Mn}-\mathrm{S} / \mathrm{TiO}_{2}$ is less than in $\mathrm{Mn} / \mathrm{TiO}_{2}$, and the charge of $\mathrm{S}$ in $\mathrm{Mn}-\mathrm{S} / \mathrm{TiO}_{2}$ is larger than in $\mathrm{S} / \mathrm{TiO}_{2}$. These results mean that the strength of the covalent bond between $\mathrm{Mn}$ and $\mathrm{S}$ in $\mathrm{Mn}-\mathrm{S} / \mathrm{TiO}_{2}$ is weaker than the $\mathrm{Mn}-\mathrm{O}$ bond in $\mathrm{Mn} / \mathrm{TiO}_{2}$ and the Ti-S bond in $\mathrm{S} / \mathrm{TiO}_{2}$.

As it can be seen in Fig. 2b, the strength of the covalent bond of $\mathrm{Mn}-\mathrm{O}$ is weaker than that of $\mathrm{Ti}-\mathrm{O}$, and this is probably due to the weaker electropositivity of Mn than that of Ti. In Fig. 2c, it is very clear that the strength of the covalent bond of $\mathrm{Ti}-\mathrm{S}$ is weaker than that of Ti-O, and this is because of the lower electronegativity of $\mathrm{S}$ than that of $\mathrm{O}$. Due to the weaker electropositivity of $\mathrm{Mn}$ and electronegativity of $S$, the strength of covalent bonds of $\mathrm{Mn}-\mathrm{S}$ and $\mathrm{Ti}-\mathrm{S}$ is weaker than those of $\mathrm{Mn}-\mathrm{O}$ and Ti-O. 


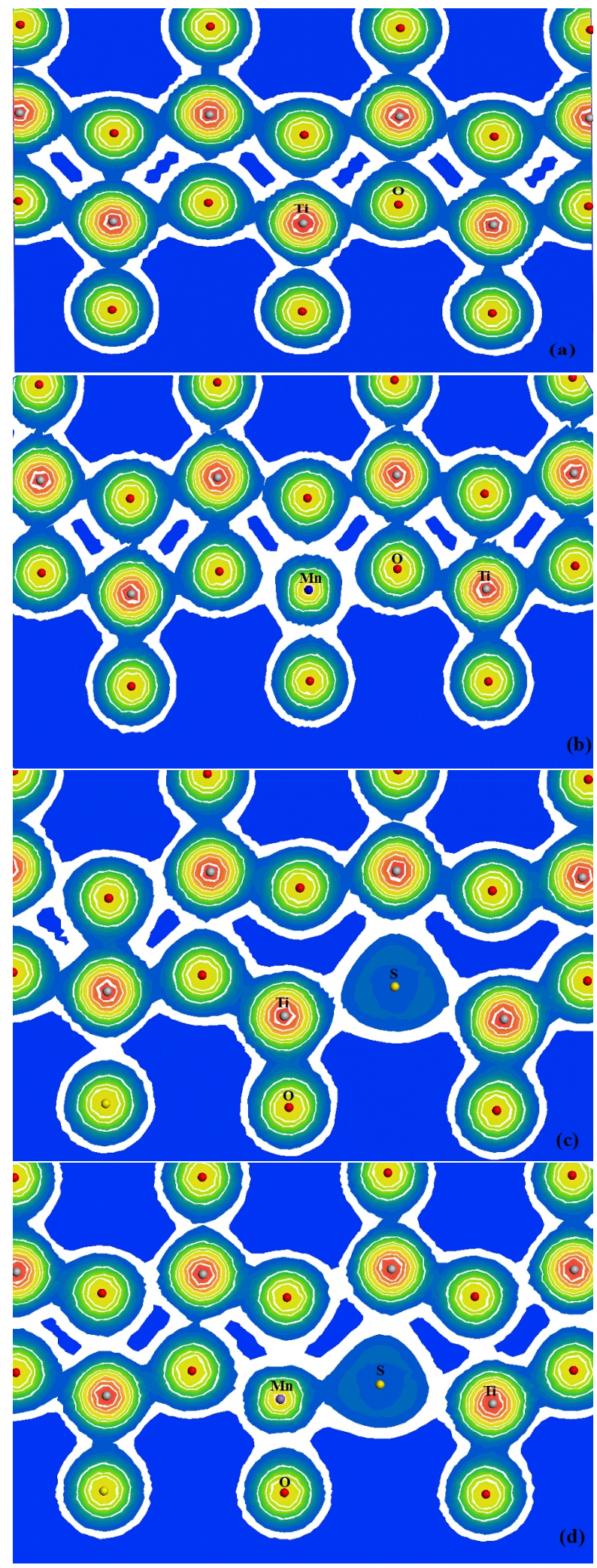

Fig. 2. Two-dimensional profiles of (a) pure $\mathrm{TiO}_{2}$, (b) $\mathrm{Mn} / \mathrm{TiO}_{2}$, (c) $\mathrm{S} / \mathrm{TiO}_{2}$, (d) $\mathrm{Mn}-\mathrm{S} / \mathrm{TiO}_{2}$.

\subsection{Band structures and density of states}

To compare the doping effects of different doping elements on the energy band of $\mathrm{TiO}_{2}$, the band structures of pure $\mathrm{TiO}_{2}, \mathrm{Mn} / \mathrm{TiO}_{2}, \mathrm{~S} / \mathrm{TiO}_{2}$, and $\mathrm{Mn}-\mathrm{S} / \mathrm{TiO}_{2}$ along the high symmetry points across the first Brillouin zone were illustrated in Fig. 3. Because a lot of theoretical calculations of $\mathrm{Mn} / \mathrm{TiO}_{2}$ [26-28] and $\mathrm{S} / \mathrm{TiO}_{2}[19,29,30]$ have been reported, we will not concentrate on the detailed research on them. But for contrast, we also calculated the energy band of $\mathrm{Mn} / \mathrm{TiO}_{2}$ and $\mathrm{S} / \mathrm{TiO}_{2}$. The Fermi level was set as the highest filled level of the electrons. The corresponding total and partial densities of states (DOS and PDOS) are shown in Fig. 4. They have been used to further analysis of the constitution of valence band (VB) and conduction band (CB), and to understand the changes of electronic structures caused by Mn-S co-doping. The VB, which is located between $-4.506 \mathrm{eV}$ and the Fermi level, was formed by the bonding states of the hybridized $\mathrm{O} 2 \mathrm{p}-\mathrm{Ti} 3 \mathrm{~d}$ orbitals with a minor contribution from $\mathrm{Ti} 3 \mathrm{p}$ and $\mathrm{Ti} 4 \mathrm{~s}$ oribitals. The CB located between 2.198 and $3.074 \mathrm{eV}$ above the Fermi level was formed primarily by the Ti $3 \mathrm{~d}$ orbitals with a minor contribution from $\mathrm{O} 2 \mathrm{p}$ orbitals. Obviously, the calculated band gap of $\mathrm{TiO}_{2}$ is $2.198 \mathrm{eV}$ [31] as shown in Fig. 3a, which is largely underestimated compared with the experimental [32] band gap of $3.2 \mathrm{eV}$ due to the inherent drawback of the ideal electron gas model in GGA approach. It is because of the DFT limitations, as the discontinuity in the exchange correlation potential has not been taken into account [33-35]. However, these results are reliable and advisable for the qualitative analysis and do not affect the accuracy of comparing the related properties of crystals.

From Fig. 3d and Fig. $4 \mathrm{~d}$ it can be seen that the $\mathrm{VB}$ of $\mathrm{Mn}-\mathrm{S} / \mathrm{TiO}_{2}$ has been formed by the bonding states of the hybridized O 2p-Ti 3d-S 3p orbitals with minor contributions from $\mathrm{Mn} 3 \mathrm{~d}$, Ti $3 \mathrm{p}$ and Ti 4 s orbitals. The $\mathrm{CB}$ of $\mathrm{Mn}-\mathrm{S} / \mathrm{TiO}_{2}$ above the Fermi level is formed primarily by the Ti $3 \mathrm{~d}$ and $\mathrm{Mn} 3 \mathrm{~d}$ orbitals with minor contributions from $\mathrm{O} 2 \mathrm{p}$ and S $3 p$ oribitals. This indicates that the electrons and holes can be separated effectively and then improve the photocatalytic efficiency of $\mathrm{TiO}_{2}$ due to 

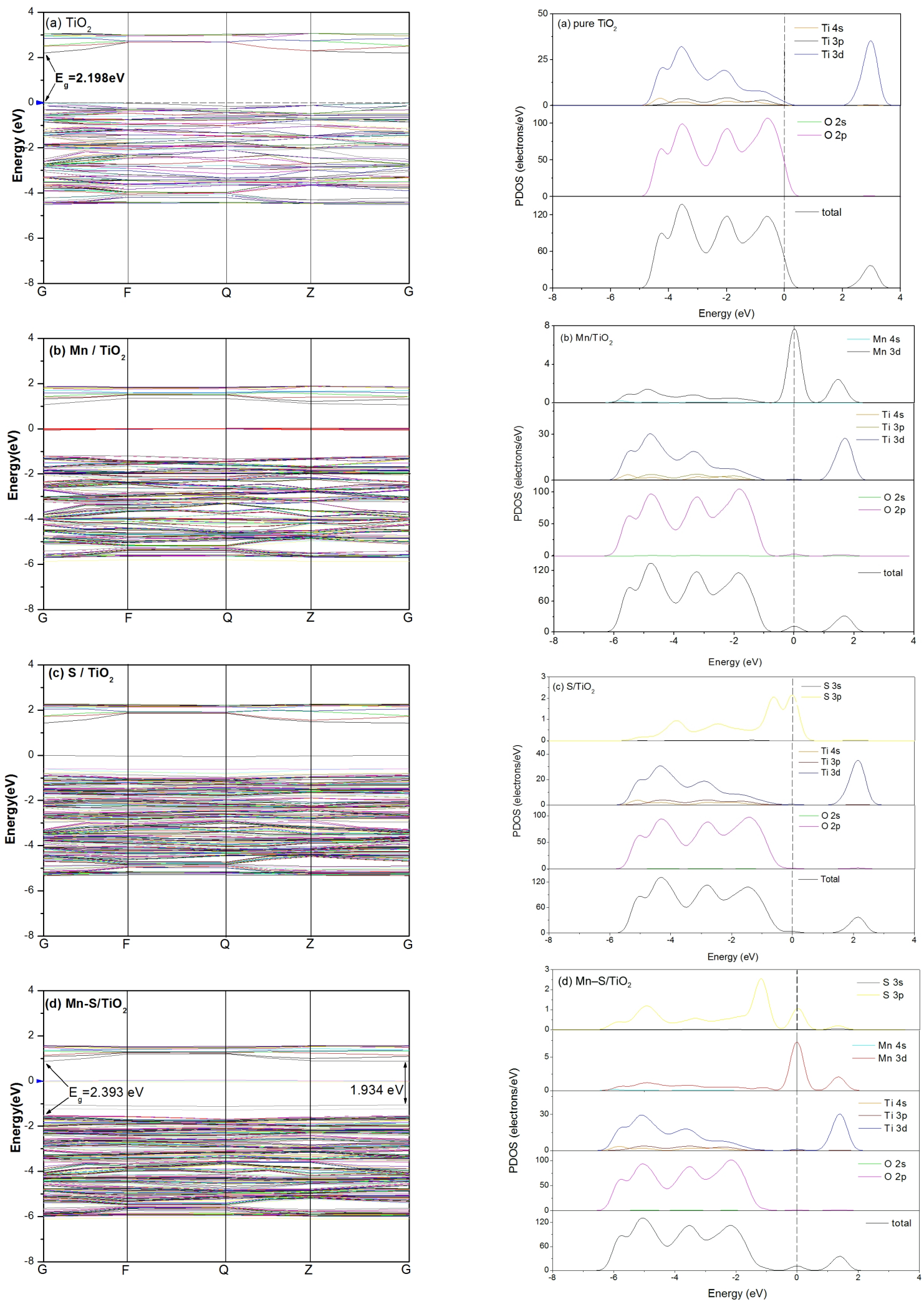

Fig. 3. Band structures of (a) pure $\mathrm{TiO}_{2}$, (b) $\mathrm{Mn} / \mathrm{TiO}_{2}$, Fig. 4. PDOS of (a) pure $\mathrm{TiO}_{2}$, (b) $\mathrm{Mn} / \mathrm{TiO}_{2}$, (c) (c) $\mathrm{S} / \mathrm{TiO}_{2}$, (d) $\mathrm{Mn}-\mathrm{S} / \mathrm{TiO}_{2}$. $\mathrm{S} / \mathrm{TiO}_{2}$, (d) $\mathrm{Mn}-\mathrm{S} / \mathrm{TiO}_{2}$. 
the energy levels crossed with each other at the bottom of the CB. The calculated band gap of the $\mathrm{Mn}-\mathrm{S} / \mathrm{TiO}_{2}$ is $2.393 \mathrm{eV}$, which is $0.195 \mathrm{eV}$ larger than that of the intrinsic $\mathrm{TiO}_{2}$. It was found that there are two impurity bands in the band gap: one is located near the Fermi level including three impurity energy levels, and another is located above the VB which contains two energy levels. The impurity band located between the VB and the Fermi level is mainly composed of S 3p orbital, which is filled up by electrons, and the electrons in this impurity band can be excited to the CB. From the calculation results, it was found that the distance between this impurity band and the $\mathrm{CB}$ is $1.934 \mathrm{eV}$, which is less than the band gap of $\mathrm{TiO}_{2}$, equal to $2.198 \mathrm{eV}$. This would be very advantageous to the electronic transition and has an important influence on the absorption of light, which is confirmed by the optical absorption spectra in Fig. 5. The impurity band is located near the Fermi level including three energy levels composed of mainly hybridized Mn 3d-S 3p orbitals. This impurity band can act as the bridge for the electron transition and enhance the light absorption. However, it can also act as recombination centers [36].

\subsection{Optical properties}

In order to explore the absorption properties, the optical absorption spectra of pure anatase $\mathrm{TiO}_{2}$, $\mathrm{Mn} / \mathrm{TiO}_{2}, \mathrm{~S} / \mathrm{TiO}_{2}$ and $\mathrm{Mn}-\mathrm{S} / \mathrm{TiO}_{2}$ were calculated on the basis of the detailed electronic band structure as shown in Fig. 5. Because of the underestimated band gap of pure $\mathrm{TiO}_{2}$, we induced a scissors operator of $1.032 \mathrm{eV}$ (band gap difference between experimental and calculated value) for obtaining an exact optical absorption spectra in the visible region. It is obvious that the absorption edges of $\mathrm{Mn} / \mathrm{TiO}_{2}, \mathrm{~S} / \mathrm{TiO}_{2}$ and $\mathrm{Mn}-\mathrm{S} / \mathrm{TiO}_{2}$ move toward the longer wavelength, which means enhancement of visible light absorption. $\mathrm{Mn}-\mathrm{S} / \mathrm{TiO}_{2}$ has stronger light absorption in the visible region compared with pure $\mathrm{TiO}_{2}, \mathrm{Mn} / \mathrm{TiO}_{2}$, and $\mathrm{S} / \mathrm{TiO}_{2}$. This implies that the $\mathrm{Mn}-\mathrm{S} / \mathrm{TiO}_{2}$ probably has a higher photocatalytic activity. Actually, there are many factors affecting the photocatalytic efficiency of $\mathrm{TiO}_{2}$, in addition to external conditions (such as light source, time, temperature, and the $\mathrm{pH}$ value of reaction system), and also including intrinsic characteristics of $\mathrm{TiO}_{2}$, especially specific surface area, impurity energy levels or bands, and defects. In this paper, we mainly consider the effects of impurity bands and we think the impurity bands play an important role, especially the one between the Fermi level and the VB. Because this impurity band can act as a "step" which reduces the electronic transition energy, it means that more electrons can be excited. More excited electrons means greater probability that photo-excited electrons can migrate to the surface. Meanwhile, the impurity energy levels or band could also act as a separating center. The photo-excited electrons-holes can separate rapidly and effectively, which will promote the carriers diffusion and enhance the charge carrier lifetime. Therefore, the quantum transformation efficiency can be improved, which will lead to the enhancement of the photocatalytic efficiency of $\mathrm{Mn}-\mathrm{S} / \mathrm{TiO}_{2}$.

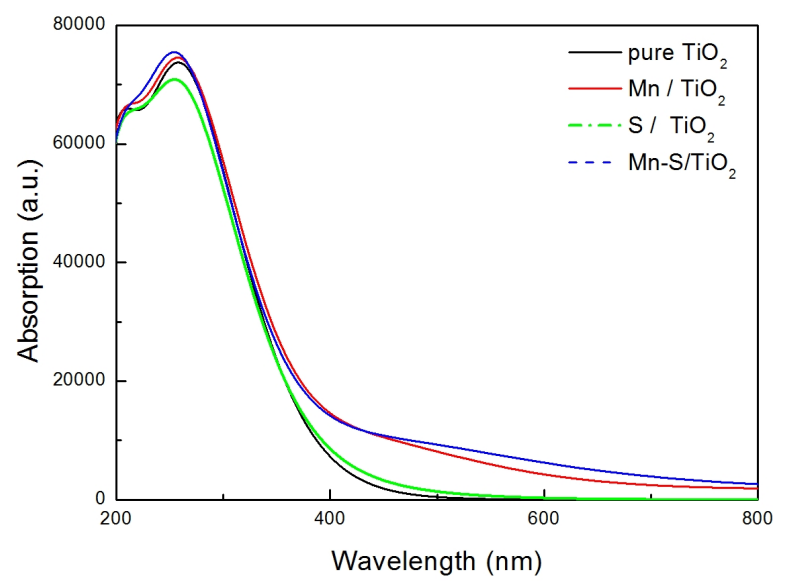

Fig. 5. Absorption spectra of pure $\mathrm{TiO}_{2}, \mathrm{Mn} / \mathrm{TiO}_{2}$, $\mathrm{S} / \mathrm{TiO}_{2}$ and $\mathrm{Mn}-\mathrm{S} / \mathrm{TiO}_{2}$.

\section{Conclusions}

First-principles method has been employed to study the effects of $\mathrm{Mn}-\mathrm{S}$ co-doping on the electronic and optical properties of anatase $\mathrm{TiO}_{2}$. The calculation on $\mathrm{Mn}-\mathrm{S} / \mathrm{TiO}_{2}$ with GGA shows that 
the introduction of $\mathrm{Mn}$ and $\mathrm{S}$ induces two impurity bands in the forbidden band. The impurity band, especially the one located between the Fermi level and the VB causes the obvious redshift and absorption enhancement in the visible region for $\mathrm{Mn}-\mathrm{S} / \mathrm{TiO}_{2}$. Therefore, $\mathrm{Mn}-\mathrm{S}$ co-doping is a fine choice for enhancing the photocatalytic activity of $\mathrm{TiO}_{2}$.

\section{Acknowledgements}

This work was supported by the China Scholarship Council ([2014]-3012) and National Natural Science Foundation of China (No. 61306098). The authors would highly acknowledge Professor Baoting Liu at the Hebei University for providing CASTEP software and the discussing of the results.

\section{References}

[1] Wei B.L., Chen Y.P., Ye M.J., Shao Z.H., He Y., Shi Y., Plasma Chem. Plasma P., 35 (2015), 173.

[2] Angthararuk D., Sutthivaiyakit P., Blaise C., Gagné F., Sutthivaiyakit S., Environ. Sci. Pollut. R., 22 (2015), 1468.

[3] Papoulis D., Kordouli E., Lampropoulou P., Rapsomanikis A., Kordulis C., Panagiotaras D., Theophylaktou K., Stathatos E., Komarneni S., J. Surf. Interfac. Mater., 2 (2014), 261.

[4] Zhan L.L., Chen H.F., Ye J.Q., Adv. Mater. Res., 531 (2012), 387.

[5] Huang J.M., LiU Y.Y., Lu L.F., Lu L., Res. Chem. Intermediat., 38 (2012), 487.

[6] Varley J.B., Janotti A., Walle C.G.V.D., $A d v$. Mater., 23 (2011), 2343.

[7] Zuo F., Bozhilov K., Dillon R. J., Wang L., Smith P., Zhao X., BardeEn C., Feng P.Y., Angew. Chem. Int. Edit., 124 (2012), 6327.

[8] Yamada N., Hitosugi T., Kasai J., Hirose Y., Shimada T., Hasegawa T., J. Appl. Phys., 105 (2009), 123702.

[9] Pal U., Ghosh S., Chatterjee D., Transit. Metal. Chem., 37 (2012), 93.

[10] Yang X. X., CaO C. D., Hohn K., ERICKSON L., MaghiRAng R., Hamal D., Klabunde K., J. Catal., 252 (2007), 296.

[11] Ceotto M., Presti L.L., Cappelletti G., Meroni D., SpadaVecchia F., Zecca R., LEONI M., SCARDi P., BIANCHI C.L., ARDIZZONE S., J. Phys. Chem. C, 116 (2012), 1764.

[12] Yang K., Dai Y., Huang B.B., Whangbo M.H., J. Phys. Chem. C, 113 (2009), 2624.

[13] Umebayashi T., Yamaki T., Itoh H., Asai K., Appl. Phys. Lett., 81 (2002), 454.
[14] Wu B., Zhuang W.Q., Sahu M., Biswas P., Tang Y.J., Sci. Total Environ., 409 (2011), 4635.

[15] Chen D.M., XU G., MiaO L., Chen L.H., NAKaO S., Jin P., J. Appl. Phys., 107 (2010), 063707.

[16] Feng H.J., Zhang M. H., Yu L.E., Appl. Catal. A-Gen., 413 - 414 (2012), 238.

[17] Li M., Zhang J.Y., Zhang Y., Chem. Phys. Lett., 527 (2012), 63.

[18] Umebayashi T., Yamaki T., Tanaka S., Asai K., Chem. Lett., 32 (1) (2003), 330.

[19] Cui Y., Du H., Wen L.S., Solid State Commun., 149 (2009), 634.

[20] Zhang K.J., XU W., Li X.J., Zheng S.J., XU G., Cent. Eur. J Chem., 4 (2006), 234.

[21] Binas V.D., Sambani K., Maggos T., KatSANAKi A., Kiriakidis G., Appl. Catal. B-Environ., 113 - 114 (2012), 79.

[22] Clark S.J., Segall M.D., Pickard C.J., Hasnip P.J., Probert M.I., Refson K., PAyne M.C., Z. Kristallogr., 220 (2005), 567.

[23] Burdett J.K., Hughbandk T., Miller G.J., Richardson JR J.W., Smith J.V., J. Am. Chem. Soc., 109 (1987), 3639.

[24] LiU X.S., Jiang E.Y., Li Z.Q., Song Q.G., Appl. Phys. Lett., 92 (2008), 252104.

[25] Valentin C.D., Pacchioni G., Selloni A., Chem. Mater., 17 (2005), 6656.

[26] Umebayashi T., Yamaki T., Itoh H., Asai K., J. Phys. Chem. Solids, 63 (2002), 1909.

[27] Zhang X.J., LiU Q.J., Deng S.G., Chen J., Gao P., Acta Phys. Sin.-Ch. Ed., 60 (2011), 087103.

[28] Zhong X.C., PAn Z.G., Wei Z.G., XU G., XU Y.Y., Comput. Appl. Chem., 28 (2011), 685.

[29] Matsushima S., Takehara K., Yamane H., Yamada K., Nakamura H., Arai M., Kobayashi K., J. Phys. Chem. Solids, 68 (2007), 206

[30] Wu G.H., Zheng S.K., Jia C.J., LiU L., Acta Phys. Sin.-Ch. Ed., 61 (2012), 223101.

[31] Zheng S. K., Wu G. H., Liu L., Acta Phys. Sin.-Ch. Ed., 62 (2013), 043102.

[32] TAng H., Berger H., Schmid P.E., LÉvy F., BURRI G., Solid State Commun., 23 (1977), 161.

[33] Stampfl C., Van de Walle C.G., Phys. Rev. B, 59 (1999), 5521.

[34] Perdew J.P., Mel L., Phys. Rev. Lett., 51 (1983), 1884.

[35] Lee J.Y., Park J., Cho J.H., Appl. Phys. Lett., 87 (2005), 011904.

[36] Long R., English J.N., Appl. Phys. Lett., 98 (2011), 142103.

Received 2015-03-17 Accepted 2015-09-29 